\section{Bonn Convention's first meeting}

John A. Burton, Executive Secretary FFPS

The first meeting of the Parties to the Convention on Migratory Species (Bonn Convention), held in Bonn from 21 to 26 October 1985, was attended by all 19 Parties that have ratified so far. In addition 44 observer countries and a large number of non-government organizations (NGOs) were present. FFPS was active at the meeting in 1979 that concluded the agreement, and I again represented the Society at this first meeting of the Parties. Although the number of Parties is relatively small, it is still a very young convention and has only recently acquired a Secretariat.

There was considerable debate about the precise meaning of the term 'migratory', some of the ornithological specialists wanting to restrict it to migrations of the kind undertaken by swallows and storks. However, it was generally agreed that the intention of those present in 1979 was to protect all animals that cross political boundaries. There are two appendices to the Convention: Appendix I requires Parties to enforce strict protection for listed species, and Appendix II requires Parties to reach agreements that will help enhance the conservation status of the species concerned.

In 1979, largely at the instigation of the FFPS, the mountain gorilla was listed on Appendix I as an example of a population of a species that regularly crossed political borders and for which an agreement between the countries concerned would be beneficial.

For the 1985 meeting the Federal Republic of Germany had prepared a proposal for Appendix II listing of all bats, which the FFPS strongly supported. A small working group, comprising Dr Carl Edelstam from Sweden, Dr G. Topal from Hungary, Wolfgang Fremuth from Germany and myself, was formed to discuss bats, and this resulted in a proposal for a pan-European agreement on bats being adopted at the plenary session.

Similar outline proposals were submitted for Western Palearctic ducks and geese, the white 70 stork, and small cetaceans in the North Sea. If the Bonn Convention can stimulate proposals such as these, and then carry them forward so that agreements result, it will be a truly useful convention. It is hoped that more countries will decide to join. Conspicuously absent is the USA, which in 1979 first voted against and then abstained from signing the Convention, largely because marine fish were included in the Convention's competence. Unlike the meetings of the Convention on the International Trade in Endangered Species of Wild Fauna and Flora and of the International Whaling Commission, where American NGO's seem to be the only nonendangered species, there were hardly any American NGOs present. So far Chile is the only country from the New World to have ratified the Convention.

In addition to the actual work of the Conference and lobbying for the bat proposal, the Conference was a useful place for other meetings. Many of the delegates were members of FFPS, and useful discussions concerning FFPS's work were held with several of them. Solutions to the Kashmir fur smuggling problems were discussed with Dr Ranjitsinh, head of the Indian delegation, while help for the project to reintroduce scimitar oryx into North Africa was discussed with several delegates involved with foreign aid programmes.

It is gratifying that, unlike so many conventions, a genuine spirit of co-operation pervaded all discussions - with no 'antis' and 'pros'; we were all working for the same cause.

\section{Botanic gardens: their potential for conservation by Sara Oldfield}

Since 1979 approximately 10 per cent of the world's rare and threatened flowering plants have been located in botanic gardens. Tracking them down has been the work of IUCN's Botanic Gardens Conservation Co-ordinating Body (BGCCB), with a small secretariat based at Kew. $B G C C B$ now has well over 100 member gardens together with a similar number affiliated in the USSR.

The work of the $\mathrm{BGCCB}$ was reviewed at the Oryx Vol 20 No 2, April 1986 
conference, 'Botanic Gardens and the World Conservation Strategy' held in Las Palmas, Gran Canaria, in November 1985. A draft Botanic Gardens Conservation Strategy was prepared for discussion at the meeting, summarizing the conservation activities already undertaken by botanic gardens and ways in which these could be strengthened. Some very interesting facts emerged in preparation of the Strategy, which involved a survey of all the botanic gardens of the world. The sheer number of botanic gardens came as a surprise, with a total of 1300 discovered. Also, of particular significance for conservation, it was found that over 100 botanic gardens have an associated nature reserve and over 200 have retained areas of natural vegetation within the garden itself.

There is obviously a great potential for strengthening the role of botanic gardens as centres for plant conservation. Many problems remain, however. Some moribund gardens need to be revitalized; for others a change of identity is required; in developing countries new gardens need to be established - and all without taking away resources for plant conservation in the wild. Most botanic gardens are publicly funded, and it may be that only with a wider appreciation of the plight of threatened plants will adequate resources be made available to botanic gardens. The gardens themselves have been much slower than zoos in publicizing the conservation work they are carrying out.

The Gran Canaria conference called for closer co-operation between botanic gardens in conservation activities, and particularly for the sharing of training and other resources between tropical and temperate botanic gardens. Already, regional conservation networks exist in, for example, USA, Canada and Mexico, and, together with $\mathrm{BGCCB}$, these will make ex situ plant conservation more effective. Zoos are also looking at ways to incorporate plants into their conservation programmes, and this creates exciting possibilities for extending the back-up to in situ species and habitat conservation still further.

Sara Oldfield, IUCN Conservation Monitoring Centre, $219 \mathrm{c}$ Huntingdon Road, Cambridge CB3 ODL, UK.

News and views

\section{Lion tamarins rescued by Célio Valle and Anthony B. Rylands}

The golden-rumped lion tamarin Leontopithecus chrysopygus is considered to be the most endangered of South East Brazil's primates. It is restricted to two reserves of the Forestry Institute of the State of São Paulo, Caitetus (5647 ha) and Morro do Diabo (37,157 ha). A large part of the Morro do Diabo Reserve, which was decreed in 1942 , has been severely logged. In addition, a railway line, built to facilitate timber extraction, runs through it, some areas have been cut for cattle pasture and an asphalted road cuts it in two. Finally, the Rosana hydroelectric dam on the Rio Paranapanema, which marks the southern border of the reserve, will flood approximately 3000 ha of the forest and pasture within it. The dam was due to be finished in 1988, but for political reasons construction has been accelerated and is expected to be completed in late 1986.

This latest assault on the reserve has at last stimulated considerable concern for the survival of the golden-rumped lion tamarin and for the protection of this small remnant of the once widespread forests of the Rio Paraná basin. A number of organizations are co-operating in a programme to rescue and translocate the lion tamarins, as well as groups of two other primates, brown howler monkeys Alouatta fusca and blackcapped capuchins Cebus apella, in the inundation area. The rescue is being carried out by teams from the Rio de Janeiro Primate Centre, headed by Claudio Valladares Pádua, who is also carrying out a study of their ecology and behaviour, and the Zoology Department of the Federal University of Minas Gerais, Belo Horizonte, headed by Professor Célio Valle. The work is being financed by the Fauna and Flora Sector of the São Paulo Electricity Company (CESP) and the World Wildlife Fund-US Primate Programme through the Brazilian Foundation for the Conservation of Nature (FBCN).

One group of golden-rumped lion tamarins has already been caught and sent to the Rio de Janeiro Primate Centre, where Dr Adelmar Coimbra-Filho, a long-standing and tenacious campaigner for the three lion tamarin species, has 
a colony (26 animals in Janury 1985) bred from a single pair caught in the early 1970s, which is consequently suffering from inbreeding effects. Other groups will be caught and relocated in nearby protected forests where surveys have established that there is a similar habitat, but no other lion tamarin groups. To date, five groups have been found within the inundation area.

By way of compensation for the loss of the 3000 ha, CESP is financing the Forestry Institute for the construction of offices, houses for the park guards, and living quarters and laboratories for scientific research.

The World Wildlife Fund-US Primate Programme, in co-operation with the Forestry Institute and CESP, has carried out a very successful education campaign in the nearby town of Teodoro Sampaio. In September 1985 the lion - tamarins were involved in a political campaign when a misunderstanding arose from an article in a São Paulo newspaper and it was believed that all the lion tamarins in the reserve might be taken into captivity. The Brazilian Democratic Movement Party distributed a leaflet urging that the monkeys should be rescued from the area to be flooded, but released elsewhere in the reserve. If the monkeys were taken away, it argued, the town would lose jobs and the reserve would lose the protection and attention it deserved. The misunderstanding was cleared up, but it demonstrated the effectiveness of the education programme. The people of the town of Teodoro Sampaio are now active in demanding that the reserve and the lion tamarins must be protected.

Célio Valle, Department of Zoology, Federal University of Minas Gerais, Belo Horizonte, Minas Gerais, Brazil.

Anthony B. Rylands, Department of Ecology, Instituto Nacional de Pesquisas da Amazonia, Caixa Postal 478, 69.000 Manaus, Amazonas, Brazil.

\section{The Corsican red deer returns to Corsica}

The Corsican red deer Cervus elaphus corsicanus is an endangered subspecies, which survives in the wild only in Sardinia. A census by WWF-Italy in 1982 revealed a total of 240-330 individuals living in three separate forests, north-west, southwest and east of Cagliari. About 100 of them are 72 found in the 300-ha reserve of Monte Arcosu, recently purchased by WWF-Italy. Two small herds live in semi-capitivity in two reserves near Is Cannoneris and Sette-Fratelli, established by the Sardinian Forest Guard with the assistance of WWF-Italy's delegation in Sardinia.

Despite its international name-the Italians prefer to call it the Sardinian deer-the subspecies has been extinct in Corsica since 1970 . About 1000 deer lived there at the turn of the century, but indiscriminate hunting brought them to the verge of extinction, particularly during the late 1950s, when some agricultural communities of Algerians and Tunisians settled in the area. Only five bucks and one doe survived in Corsica in 1965; the female was killed by a poacher that same year and all traces of the males had disappeared five years later.

Now at last, after seven years of negotiations between the Sardinian and Corsican Regional Governments initiated by WWF-Italy, and after several surveys and some intensive research, two pairs of Sardinian deer have been reintroduced into Corsica. The operation has been organized jointly by the Sardinian Regional Forest Organization and Corsica National Park. The deer-an adult pair, of which the doe is pregnant, and a young pair-were selected by the Sardinian Forest Guards from the 18 living in the reserve of Is Cannoneris. They were taken to Corsica in an Italian Air Force helicopter on 8 and 9 November 1985 and introduced into a fenced area of 38 ha in Corsica National Park, which covers 220,000 ha of forest and Mediterranean maqis in the centre of the island.

The local people have been informed of the project and a documentary on the Corsican deer, filmed by French TV, has been shown to all the school children. There are hopes that the two pairs of deer will be the founders of a future new Corsican herd, but regular exchange of pairs of deer between Corsica and Sardinia is planned in order to avoid excessive inbreeding. The birth of a fawn to the recently transferred adult pair is expected in June or July 1986; it will be the first real Corsican red deer of the new generation.

WWF-Italy, Via Salana 290, 00199 Rome, Italy.

Oryx Vol 20 No 2, April 1986 
Finding out the truth about the crownof-thorns

by Sue Wells

The crown-of-thorns starfish Alcanthaster planci and its impact on coral reefs has been a controversial issue for more than a decade. Many scientists believe outbreaks to be natural and recurring phenomena, but one school of thought has consistently maintained that outbreaks were negligible until the 1930s, and that the recent increase is due to human activities. In Australia public concern reached almost panic proportions in the 1970s when it was feared that the starfish would destroy the Great Barrier Reef. It is now abundantly clear that this will not happen, but it is also clear that the starfish is a serious threat to some reefs of the system in the short-term and that there is a major management problem. For example, the reefs around Green Island, off Cairns, suffered major outbreaks between 1965 and 1967 and between 1979 and 1981 and the majority of stony corals died. However, there are still some living colonies and the remaining dead coral framework provides habitat for fish, so the island has remained a popular tourist attraction.

Numerous theories have been produced to account for outbreaks. Overcollecting of predators is probably unlikely, although this is still considered to be the cause by some people. A theory linking outbreaks with low salinity and high water temperatures has gained greater credence. Outbreaks may occur following heavy rains after long dry spells, and this may be explained by increased run-off from the land, supplying increased nutrient levels to support the growth of phytoplankton, which in tum provide food for the starfish larvae. Deforestation and coastal development could increase the impact of soil run-off. However, this theory does not account for outbreaks that have been recorded on oceanic reefs.

No methods of control or elimination have been entirely successful. Collection by hand or the killing of starfish by injection with copper sulphate solution are the two methods most commonly used, but they are labour-intensive, their costs are high and it is almost impossible to kill an entire population of these cryptic animals.
As a result of the controversy and the problems created by renewed outbreaks of the starfish in 1983, the Great Barrier Reef Marine Park Authority set up a Crown-of-Thoms Starfish Advisory Committee to make recommendations for research and handling of the problem. The Committee's report pointed out that, since the Great Barrier Reef has been nominated a World Heritage Site, it must be regarded as a national priority. It recommended that until further information is available there should be no control programmes except for tactical control measures at specific sites. The Australian Institute of Marine Sciences (AIMS) has been awarded a grant of over $A \$ 1$ million by the Federal Government to conduct a major study of the starfish. Over 50 survey and support staff have been recruited under the Federal Government's Commonwealth Community Employment Programme.

The one-year study, started in March 1985, is surveying 228 reefs scattered throughout the entire Great Barrier Reef region to establish the extent and pattern of activity of the starfish. In addition, a survey of the distribution and abundance of corals and other reef organisms is being made, looking at all stages of infestation. There is also a more detailed study of the massive corals; these are of particular interest, not only because of their slow growth and consequently long replacement time, but also because their skeletons contain a record of their previous growth patterns. A proportion of massive corals has been found to have anomalies in the form of living lobes overlying dead ones; in some cases three distinct layers have been found, which, it has been suggested, could be due to earlier starfish outbreaks.

The study is also attempting to find out more about the population biology of the starfish. It has proved almost impossible to tag by any standard methods and little is known of the juvenile stages. It may yet be proved that under normal conditions, whatever these may be, the starfish has a positive role to play in maintaining the ecological diversity of the reef.

Sue Wells, IUCN Conservation Monitoring Centre, 219c Huntingdon Road, Cambridge CB3 ODL, UK. 